\title{
Sexual behaviour among youth clinic visitors in Sweden: knowledge and experiences in an HIV perspective
}

\author{
Elisabeth Persson, Gunilla Jarlbro
}

\begin{abstract}
Objective-To study the knowledge and experience of sexuality, contraception and sexually transmitted diseases among sexually active adolescents in Sweden.

Subjects-Youth clinic visitors. Setting-Seventy-four youth clinics from all over the country of Sweden.

Methods-A questionnaire with 17 multiple choice and nine open questions was distributed to all visitors at participating youth clinics during a 2 -month period.

Results-A total of 9277 young persons answered the questionnaire. Their mean age was $17 \cdot 5$ years. Ninety-three percent were females. Knowledge on STD and STD protection was wide-spread and good. Chlamydia and HIV was recognised as STDs by $90 \%$ and $87 \%$ respectively. More than $99 \%$ knew of the condom method as a means for STD protection. Knowledge on contraceptive methods for pregnancy protection was also good. Ninety-three percent of the investigated adolescents had had coitus. Nine percent had experienced pregnancies and $17 \%$ STDs. The mean number of life-time sexual partners was $3 \cdot 2$.

Conclusions-In spite of good knowledge on preventive measures among Swedish youth clinic visitors their sexual behaviour carries risks for future health. Further interventions are needed to minimise these risks.
\end{abstract}

\section{Introduction}

As sexual transmission is the most common route of spread for human immunodeficiency virus (HIV) studies of sexual behaviour have become an important means of understanding the conditions for spread. ${ }^{12}$ Knowledge on this subject is a prerequisite for interventions to achieve behavioural changes. With the "sexual revolution" of the 1960 s, the increased access to contraception, as well as other socioeconomic factors, the age for engaging in sexual activities has lowered in many industrialised countries. ${ }^{34}$ It is therefore a responsibility of the utmost importance to help young sexually active people to develop a sexual behaviour with minimal risks. With this objective many community-based HIVcampaigns have concentrated on the youth population.

The aim with this investigation was to study the knowledge and experience of sexuality, contraception and sexually transmitted diseases (STD) among sexually active adolescents in Sweden three years after the start of the HIV information programmes to assess needs to be satisfied in future prevention programmes.

\section{Background data}

Sweden is an industrialised developed country with a population of 8.5 million. Around $9 \%$ of the population are teenagers. ${ }^{5}$ Schooling for children and young adults consists of the nine year compulsory school and voluntary upper secondary school. These are both comprehensive schools designed to accommodate all members of the rising generation. Ninety percent of all pupils continue to an upper secondary school; half in theoretical lines for three or four years and half in vocationally oriented lines for two years. Furthermore, municipal authorities have a follow-up responsibility till the age of 18 years for those having no regular education after compulsory school and no permanent employment. This "youth guarantee" aims at channelling young persons into further education or finding them jobs as soon as possible. ${ }^{6}$

Swedish society has for more than three decades tried to meet the needs among young people for education and counselling in matters on sexuality. Education on sexuality and cohabitation is mandatory in both compulsory and upper secondary schools. Youth clinics have been established all over the country to give adolescents further education on sexuality and to provide easily accessible contraceptive counselling. Most youth clinics are run by midwives under professional guidance by gynaecologists or general practitioners. Other health care personnel such as psychologists, paediatricians and venerologists as well as social workers are often part of the working team. ${ }^{7}$ Most youth clinics have an upper age limit of 20 years for visitors. More than $90 \%$ of the youth clinic visitors are female.

Chlamydial and human papilloma virus infections are the most prevalent STDs in Sweden today whereas gonorrhoea and syphilis are no longer of major significance. ${ }^{89}$ The need for prevention strategies to avoid spread of STDs was taken into account long before the AIDS epidemic. Screening
Address correspondence to: Accepted for publication 28 October 1991 
Figure 1 Age distribution of investigated youth clinic visitors $(n=9240)$.

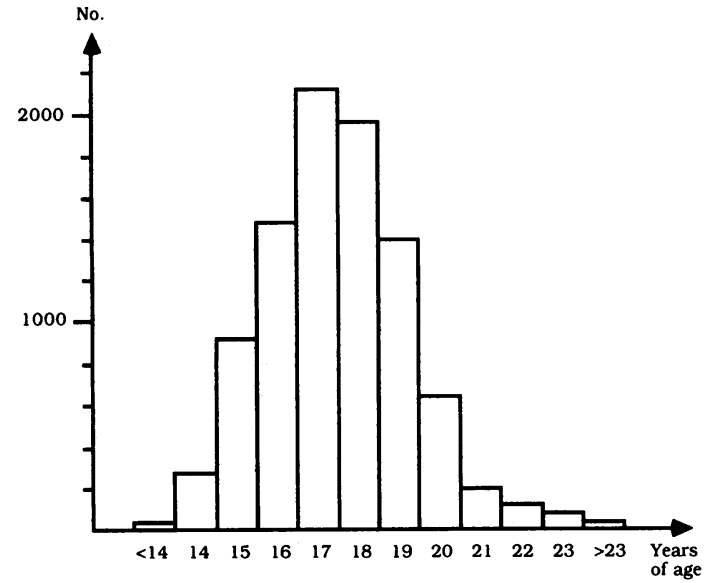

programmes for $C$ trachomatis are run by most youth clinics.

With the AIDS epidemic, information campaigns for the general population started out in 1987. The aim was to spread knowledge on the disease, on transmission routes and how to protect oneself. Heterosexual young people was an important target group. ${ }^{10}$ Since then, educational programmes for health care workers, teachers and different peer groups to create the means of reaching people with risk behaviour have been carried through by different community-based authorities. For health care personnel working with differen aspects on sexuality the need for integration of programmes for the prevention of STDs with already existing programmes for the prevention of unwanted pregnancies have become a matter of course.

\section{Material and methods}

The investigation was carried out during two months in 1990 as an inquiry to visitors at 74 of the 99 youth clinics registered at the National Board of Health and Welfare. The clinics not participating abstained because of too heavy a work load. The participating youth clinics were spread all over the country, representing both urban and rural areas. The number of visitors at each clinic varied between 10 and 500 per month.

A questionnaire with 17 multiple choice questions and nine open questions regarding social and educational status, reason for visit, knowledge and experiences of sexuality, contraception and STDs was prepared. The questionnaire was distributed to all visitors at the participating clinics during the study period and were filled in anonymously. The questionnairs were sent back to the investigators for handling.

Table 1 The best way to protect oneself from STDs $(n=8861)$

\begin{tabular}{lrc}
\hline Method & No. & $\%\left(99 \% C I^{\star}\right)$ \\
\hline Condoms & 8289 & $94(93 \cdot 3-94 \cdot 7)$ \\
Condoms + oral contraceptives & 174 & $2(1 \cdot 6-2 \cdot 4)$ \\
Condoms + abstinence & 149 & $2(1 \cdot 6-2 \cdot 4)$ \\
Condoms + steady partner & 86 & $1(0 \cdot 7-1 \cdot 3)$ \\
Condoms + spermicides & 59 & $1(0 \cdot 7-1 \cdot 3)$ \\
Other alternatives & 104 & $1(0 \cdot 7-1 \cdot 3)$ \\
\hline
\end{tabular}

*confidence interval.
Table 2 The best way to protect oneself against unwanted pregnancy $(n=8758)$

\begin{tabular}{lrc}
\hline Method & No. & $\%\left(99 \% C I^{\star}\right)$ \\
\hline Oral contraceptives $\dagger$ & 4227 & $48(46 \cdot 6-49 \cdot 4)$ \\
Condoms + oral contraceptives & 3144 & $36(34 \cdot 7-37 \cdot 3)$ \\
Condoms & 758 & $9(8 \cdot 2-9 \cdot 8)$ \\
IUDs & 209 & $2(1 \cdot 6-2 \cdot 4)$ \\
Abstinence & 125 & $2(1 \cdot 6-2 \cdot 4)$ \\
Oral contraceptives + spermicides & 119 & $1(0 \cdot 7-1 \cdot 3)$ \\
Condoms + spermicides & 75 & $1(0 \cdot 7-1 \cdot 3)$ \\
Other alternatives & 101 & $1(0 \cdot 7-1 \cdot 3)$ \\
\hline * & &
\end{tabular}

For statistical analyses the chi square method was used. The investigation was approved by all regional ethical committees in Sweden.

\section{Results}

During the study period a total of 9277 visitors filled in the questionnaire. Ten percent of the slightly more than 10000 young people who visited the youth clinics refrained from participating in the study. The mean response rate on each single question was $97 \cdot 2 \%$ (range $86 \cdot 1$ $99.9 \%$ ). The age distribution of the visitors is demonstrated in fig 1 . Their mean age was 17.5 years (range 11-30 years). Ninety-three percent of the visitors were females.

No statistically significant differences were found between male and female visitors in any of the dimensions studied. Data from both sexes were therefore treated together.

Forty-seven percent of the investigated young people lived in complete families with both parents. Twenty percent lived on their own or together with boyfriend/girlfriend. The majority of the rest lived in different family settings with one parent. Twelve percent stated that one or both parents had immigrated from another country.

Seventeen percent of the visitors were still at compulsory school. Seventy-five percent of them intended to continue in upper secondary school. In total $40 \%$ were at or had plans for a theoretical line of upper secondary school, $28 \%$ for a vocationally oriented line, while $28 \%$ of the investigated persons were or had plans to start working. Three percent were involved in the "youth guarantee" or unemployed.

The answers to two open questions on the best way to protect oneself from STDs and unwanted pregnancies, respectively, are shown in tables 1 and 2 . Almost everybody was aware

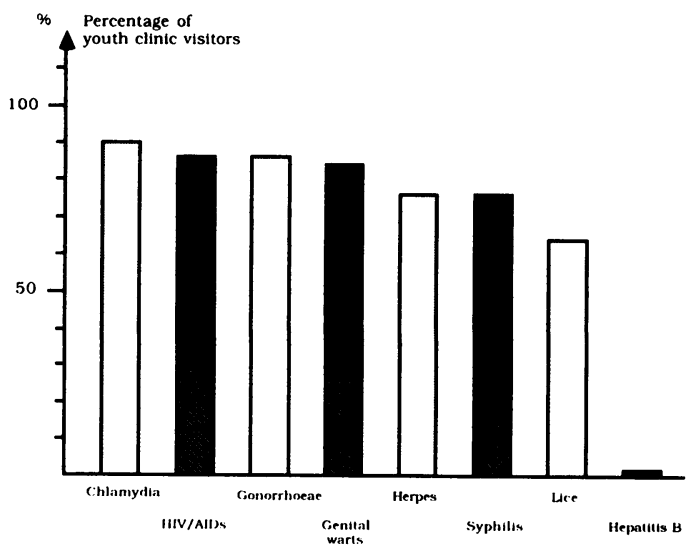

Figure 2 Percentages of youth clinic visitors who recognized certain diseases as sexually transmissible $(n=8445)$. 
Table 3 Contraceptive method at first $(n=8517)$ and most recent coitus $(n=8075)$

\begin{tabular}{|c|c|c|}
\hline & $\begin{array}{l}\text { First coitus } \\
\left(99 \% C I^{\star}\right)\end{array}$ & $\begin{array}{l}\text { Most recent } \\
\text { coitus } \\
\left(99 \% C I^{\star}\right)\end{array}$ \\
\hline $\begin{array}{l}\text { Condom } \\
\text { Oral contraceptives } \\
\text { Condoms }+ \text { oral } \\
\quad \text { contraceptives }\end{array}$ & $\begin{array}{c}48(46 \cdot 6-49 \cdot 4) \\
11(10 \cdot 1-11.9) \\
2(1 \cdot 6-2 \cdot 4)\end{array}$ & $\begin{array}{c}18(16 \cdot 9-19 \cdot 1) \\
53(51 \cdot 6-54 \cdot 4) \\
2(1 \cdot 6-2 \cdot 4)\end{array}$ \\
\hline $\begin{array}{l}\text { Diaphragm/spermicides } \\
\text { IUD } \\
\text { Withdrawal } \\
\text { Combination of methods } \\
\text { No method }\end{array}$ & $\begin{array}{c}0(0 \cdot 0-0 \cdot 0) \\
0(0 \cdot 0-0 \cdot 0) \\
12(11 \cdot 1-12 \cdot 9) \\
3(2 \cdot 5-3 \cdot 5) \\
25(23 \cdot 8-26 \cdot 2)\end{array}$ & $\begin{array}{c}0(0 \cdot 0-0 \cdot 0) \\
0(0 \cdot 0-0 \cdot 0) \\
8(7 \cdot 2-8 \cdot 8) \\
0(0 \cdot 0-0 \cdot 0) \\
18(16 \cdot 9-19 \cdot 1)\end{array}$ \\
\hline
\end{tabular}

of the condom method as a means for STD protection; a few combined it with other measures. For protection against unwanted pregnancies, oral contraception was the most popular method chosen by $85 \%$ altogether. Thirty-six percent selected condoms and oral contraceptives in combination and $9 \%$ the condom method only.

The result of the multiple choice questions where the visitors were asked to state what diseases they regarded as sexually transmissible is shown in fig 2 . Ninety percent recognised chlamydia as an STD, $87 \%$ HIV/AIDS, $86 \%$ gonorrhoea and $84 \%$ genital warts. A majority also recognised herpes, syphilis and lice as STDs while only $3 \%$ thought hepatitis B as sexually transmissible. The other alternatives given were influenza, malaria, measles and parotitis. Very few had stated these as STDs. On an open question, $84 \%$ stated that chlamydia was the most prominent STD amoung young people in Sweden, 10\% stated gonorrhea, $9 \%$ genital warts and $5 \%$ herpes.

Ninety-three percent of the investigated adolescents had had coitus. Mean and median age for first coitus was 15 years. Ninety-seven percent had had more than one coitus and for $\frac{3}{4}$ of them the second coitus had been at the same age as the first. Contraceptive method with first and most recent coitus is presented in table 3 . At first coitus the condom method was prevailing. Twenty-five percent used no method. At the most recent coitus oral contraceptives were used by more than half and use of the condom method had declined. Eighty-six percent stated experience of the condom method and $11 \%$ had used condom with every intercourse.

Two multiple choice questions on experiences of pregnancy and STD were asked. The answers are presented in table 4. Eight percent of the pregnancies resulted in childbirth, the remaining in therapeutic abortions. When asked what STDs they had suffered from, $63 \%$ stated chlamydia, $32 \%$ genital warts, $8 \%$ candidiasis and a few percent each gonorrhea,

Table 4 Experience of pregnancy $(n=8387)$ and STD $(n=7992)$

\begin{tabular}{|c|c|c|c|c|}
\hline Question & $\begin{array}{l}\text { No } \\
\% \\
\left(99 \% C I^{\star}\right)\end{array}$ & $\begin{array}{l}\text { Yes, once } \\
\% \\
\left(99 \% C I^{\star}\right)\end{array}$ & $\begin{array}{l}\text { Yes, more } \\
\text { than once } \\
\% \\
\left(99 \% C I^{\star}\right)\end{array}$ & $\begin{array}{l}\text { Don't know } \\
\% \text { o } \\
\left(99 \% C I^{\star}\right)\end{array}$ \\
\hline $\begin{array}{l}\text { Have you ever been pregnant/ } \\
\text { made someone pregnant? } \\
\text { Have you ever had an STD? }\end{array}$ & $\begin{array}{l}89(88 \cdot 1-89 \cdot 9) \\
83(81 \cdot 9-84 \cdot 1)\end{array}$ & $\begin{array}{c}8(7 \cdot 2-8 \cdot 8) \\
14(13 \cdot 0-15 \cdot 0)\end{array}$ & $\begin{array}{l}1(0 \cdot 7-1 \cdot 3) \\
3(2 \cdot 5-3 \cdot 5)\end{array}$ & $\begin{array}{l}2(1 \cdot 6-2 \cdot 4) \\
0(0 \cdot 0-0 \cdot 0)\end{array}$ \\
\hline
\end{tabular}

*confidence interval. herpes and lice. Ten percent of those with STD experience had had more than one disease.

The number of stated lifetime sexual partners is presented in fig 3 . The mean number of partners for all answering subjects was 3.7 (median 3, range 1-75). A lack of sincerity could be suspected among those stating a very high number of partners. Ninety-seven percent of answering persons had had between 1 and 12 partners. The mean number of partners for this group was $3 \cdot 2$.

The investigated persons were asked to give the most important reason for visit at the youth clinic. Fifty-four percent came for contraceptive counselling, $17 \%$ for a check-up, $12 \%$ to exclude an STD, $10 \%$ because of problems or pains, and $8 \%$ for pregnancy testing. Treatment control, dysmenorrhoea and partner tracing were other reasons for coming. More than one reason for visit was not uncommon. Ninety percent intended to visit a midwife/ gynaecologist.

Information about the youth clinic had reached the visitors in different ways. The most important information sources were friends; this was stated by $43 \%$ of the visitors. These sources were more important than the active information given about the youth clinics by school nurses $(16 \%)$ at visits for purpose of study $(15 \%)$, in advertisements $(13 \%)$ or at information meetings ( $10 \%)$.

According to the educational situation and intentions the material was classified in four groups; youth at or with plans for a theoretical line in upper secondary school (group A), a vocationally oriented line (group B), work (group C) and youth involved in the "youth guarantee" or unemployed (group D). Table 5 presents results from questions where significant differences $(p<0.001)$ between the groups were found. As the mean age of the groups differed more than age at first coitus the mean duration of active sexual life varied and was for group A 1.7 years, group B 1.8 years, group $C 3.3$ years and group D 3.0 years.

To have intercourse without contraception was more uncommon in group A both at first and most recent coitus while this behaviour was more common in group $\mathrm{D}$ at most recent coitus. When groups $A$ and $B$ were treated together

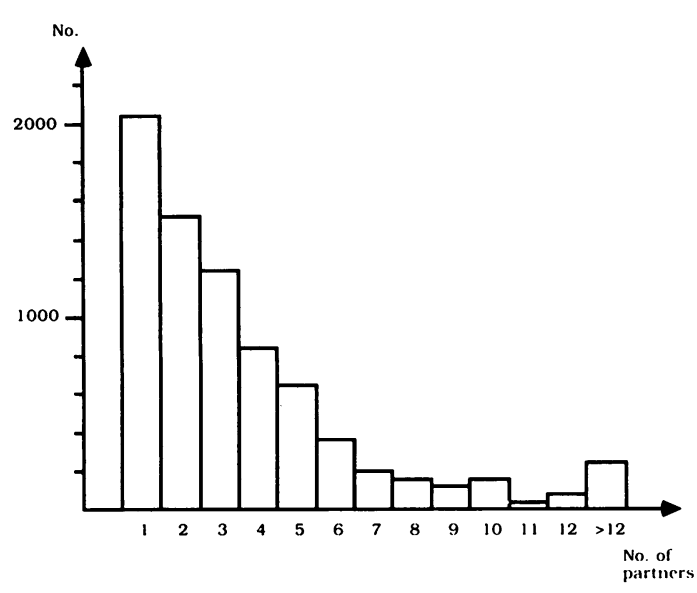

Figure 3 Number of life-time sexual partners among youth clinic visitors $(n=7778)$. 
Table 5 Variables with statistically significant differences among youth clinic visitors with different educational intentions

\begin{tabular}{|c|c|c|c|c|}
\hline Youth clinic & $\begin{array}{l}\text { Group A } \\
\text { (theoretical) } \\
n=3456\end{array}$ & $\begin{array}{l}\text { Group B } \\
\text { (vocational) } \\
n=2436\end{array}$ & $\begin{array}{l}\text { Group } C \\
(\text { work }) \\
n=2423\end{array}$ & $\begin{array}{l}\text { Group D } \\
\text { (“youth guarantee") } \\
n=284\end{array}$ \\
\hline $\begin{array}{l}\text { Mean age (years) } \\
\text { Mean age at first } \\
\text { coitus (years) }\end{array}$ & $\begin{array}{l}17 \cdot 2 \\
15 \cdot 5\end{array}$ & $\begin{array}{l}16 \cdot 7 \\
14 \cdot 9\end{array}$ & $\begin{array}{l}18 \cdot 9 \\
15 \cdot 6\end{array}$ & $\begin{array}{l}17 \cdot 9 \\
14 \cdot 9\end{array}$ \\
\hline $\begin{array}{l}\text { No contraception } \\
\text { first coitus } \\
\left(\% ; 99 \% \mathrm{CI}{ }^{\star}\right) \\
\text { most recent coitus } \\
\left(\% ; 99 \% \mathrm{CI} I^{\star}\right)\end{array}$ & $\begin{array}{l}20 \dagger \\
(18 \cdot 2-21 \cdot 8) \\
13 \dagger \\
(11 \cdot 5-14 \cdot 5)\end{array}$ & $\begin{array}{l}26 \\
(23 \cdot 7-28 \cdot 3) \\
18 \\
(16 \cdot 0-20 \cdot 0)\end{array}$ & $\begin{array}{l}27 \\
(24 \cdot 7-29 \cdot 3) \\
20 \\
(17 \cdot 9-22 \cdot 1)\end{array}$ & $\begin{array}{l}32 \\
(24 \cdot 9-39 \cdot 1) \\
35 \dagger \\
(27 \cdot 7-42 \cdot 3)\end{array}$ \\
\hline $\begin{array}{l}\text { Condom use every coitus } \\
\left(\% ; 99 \% \mathrm{CI}^{\star}\right)\end{array}$ & $(16 \cdot 4-17 \cdot 6)$ & $\begin{array}{l}11 \\
(9 \cdot 4-12 \cdot 6)\end{array}$ & $\begin{array}{l}6 \\
(4 \cdot 8-7 \cdot 2)\end{array}$ & $\begin{array}{c}4 \dagger \\
(1 \cdot 0-7 \cdot 0)\end{array}$ \\
\hline Mean No of partners & 2.9 & $3 \cdot 2$ & $4 \cdot 8$ & $5 \cdot 8$ \\
\hline $\begin{array}{l}\text { Experience of STD } \\
\left(\% ; 99 \% \mathrm{CI}^{\star}\right) \\
\text { pregnancy } \\
\left(\% ; 99 \% \mathrm{CI}^{\star}\right)\end{array}$ & $\begin{array}{l}11-\dagger \\
(9 \cdot 6-12 \cdot 4) \\
6-\dagger \\
(5 \cdot 0-7 \cdot 0)\end{array}$ & $\begin{array}{l}-12 \\
(10 \cdot 3-13 \cdot 7) \\
8 \\
(6 \cdot 6-9 \cdot 4)\end{array}$ & $\begin{array}{l}26 \\
(23 \cdot 7-28 \cdot 3) \\
14 \\
(12 \cdot 2-15 \cdot 8)\end{array}$ & $\begin{array}{l}26 \\
(19 \cdot 3-32 \cdot 7) \\
19 \dagger \\
(13 \cdot 0-25 \cdot 0)\end{array}$ \\
\hline $\begin{array}{l}\text { Pregnancies to childbirth } \\
\left(\% ; 99 \% \mathrm{CI}^{\star}\right)\end{array}$ & $(0.0-0.0)$ & $(-1 \cdot 0-3 \cdot 0)$ & $\begin{array}{l}9 \\
(5 \cdot 0-13 \cdot 0)\end{array}$ & $\begin{array}{l}23 \dagger \\
(7 \cdot 3-38 \cdot 7)\end{array}$ \\
\hline $\begin{array}{l}\text { Reason for visit: } \\
\text { pregnancy testing } \\
\left(\% ; 99 \% I^{\star}\right)\end{array}$ & $\begin{array}{l}5 \\
(4 \cdot 0-6 \cdot 0)\end{array}$ & $\begin{array}{l}7 \\
(5 \cdot 7-8 \cdot 3)\end{array}$ & $\begin{array}{l}10 \\
(8 \cdot 4-11 \cdot 6)\end{array}$ & $\begin{array}{l}17 \dagger \\
(11 \cdot 2-22 \cdot 8)\end{array}$ \\
\hline
\end{tabular}

${ }^{\star}$ confidence interval

†Results statistically significantly different when indicated group(s) were compared with remaining groups $(\mathrm{p}<0.001)$.
When interpreting the results it should be born in mind that the material is heavily biased towards young women. Youth clinic visitors might be more health conscious than nonattenders. Hence it is not appropriate to apply our findings to all young Swedes.

Housing patterns and proportion of immigrants were the same among the investigated youth clinic visitors as in the Swedish general population in this age group. ${ }^{5}$ However, a higher proportion of the investigated youths than expected was or had plans to start working. As there is a correlation between parents' occupations and their children's educational choices this indicates that working class youths are overrepresented among youth clinic visitors. ${ }^{11}$

\section{Knowledge}

The young persons' knowledge on condom use for STD protection was very good. As the investigated youths recognised most STDs as sexually transmissible one can presume that the sexual education within the school system and by other community-based authorities like the youth clinics have helped in making the condom method appreciated as protection for all STDs. In a study by Andersson-Ellström and Forssman $^{12}$ of 18 to 19 year old school pupils the teaching at school was found an essential source for STD information; a third of the pupils mentioned school as the best source. Condom use also has been intensely advocated in the HIV campaigns. This has increased the awareness of the method as has the active distribution of condoms to young people through school-nurses, youth clinics and by mailings. ${ }^{10}$ The good knowledge both of different STDs and the condom method as a means for STD-protection implies a more positive attitude towards condom use than would be the case if the condom was considered only for HIV-protection.

When relating the investigated persons' thoughts on prevalences of STDs among young people to the reported experiences, the estimates on gonorrhea were too high and those on genital warts too low. Gonorrhea used to be a prevalent disease and it is therefore a well known entity whereas genital warts that are much more prevalent today are not as well known. An increase in knowledge on genital warts has been observed among Swedish pupils during the last years. ${ }^{12}$ Our data indicate that further elaboration of school-education of condylomas and hepatitis $B$ would be of relevance.

The visitors' knowledge on contraceptive methods was also good. The "best" method chosen reflects the mixed opinions among individual counsellors and peers but still reveals a substantial knowledge in the field. Forty-six percent included the condom method in their choice. This finding also reflects a positive attitude to the condom.

\section{Experiences}

Ninety-three percent of investigated persons had had intercourse. This is natural, as the youth clinics attracts sexually active adoles-

\begin{abstract}
low number of drop-outs and the high response rate on each question was gratifying and indicate a positive and cooperative attitude among the investigated persons.

In this nation-wide study of youth clinic visitors in Sweden a total of over 9000 inquiries
\end{abstract}


cents. That also explains the low age at first coitus (15 years). Among young women $(<25$ years) at contraceptive clinics in Sweden median age at first coitus has in two recent studies been found to be 16 and 16.5 years, respectively..$^{1314}$ Similar results were found by the UK family planning research network. ${ }^{15}$ Persson et al ${ }^{13}$ noticed that a higher proportion of those with an early sexual debut postponed their start of continuously active sex-life till later. In this youth material we found no indication of such behaviour.

Contraceptive methods used at first and most recent coitus are in agreement with other Swedish studies. ${ }^{14} 16_{17}$ When interpreting the figures for most recent coitus one must bear in mind that the most prevalent reason for visit at the clinics was to get contraceptive counselling. A great majority had experience of the condom method but few practiced it with every intercourse. Apparently, though there is a widespread knowledge both of STD and pregnancy protection and though condoms are easily available, young people have problems practicing the method. This is also reflected in their frequent experience of pregnancies and STDs. Kegeles et al reported the same disquieting results among adolescents, that is, good knowledge and beliefs in the preventive effects of condoms but little motivation to use them. ${ }^{18}$ They brought to attention the need to address better the teenagers' concerns that may inhibit their use of condoms. The study here conducted further emphasises this need.

With an endemic occurrence of a transmissible disease the risk of contracting the disease depends on the individual's number of simultaneous or previous partners or his/her partner's corresponding number. The mean number of life-time sex partners for this young group of people was over three and this in itself creates conditions for STD spread. A change in life-style has evolved during the last decades. The median number of sexual partners among adult Swedish women was 1.4 in 1967 and 2.6 in $1979 .{ }^{19}$ This change is probably one of the most important latent causes for the STD endemics among young Swedes. Comparable changes in life-style has been reported from other countries. ${ }^{4152021}$

Peer influence is of great importance for adolescent sexual behaviour. ${ }^{22}$ The great proportion of visitors who learnt about the youth clinics from friends implies that the clinics' work is well accepted and appreciated by the target group. From the stated reasons for visit, a concern about one's own sexual health could be traced. Enhancement of this concern could be a useful strategy to decrease risk behaviour.

When the material was stratified according to educational situation and intentions reflecting social classes a risk group among the adolescents was defined. The investigated persons involved with the "youth guarantee" (group D) who had quit school after the compulsory years and not found any jobs were more prone not to use contraception, less prone to practice the condom method at every coitus and also had more experience of STDs, pregnancies and childbirth. Though they had the same level of knowledge about STD and pregnancy protection they were not able to handle the methods in practice as well as young people with educational ambitions. Intensive intervention programmes for this special risk group should be of high priority.

Different cultural settings were also found to influence the behaviour and experiences which was demonstrated by the results among offspring to immigrants. Special educational efforts by tutors familiar with the different cultures would be pertinent.

Sweden is a large country but no differences could be found between youths from different regions or in urban or rural areas. This is a reflection of the well developed information channels and communications in modern society.

\section{Conclusions}

This nation-wide study of Swedish youth clinic visitors, of whom $93 \%$ were females, has shown that knowledge on STD, STD-protection and contraception is wide-spread and good. Attitudes to condom use could be interpreted as positive and plenty of the investigated youths had tried the method. These findings could without doubt be attributed to the longstanding open attitudes to sex education in school and the intensive HIV-campaigns during the late 1980s. Among the visitors a concern for one's own sexual health could be detected. The initiative to visit a youth clinic is in itself an expression of this concern.

Experiences of STDs and pregnancies, however, demonstrate that adolescent sexual behaviour carries risks for future health. The positive attitudes and concerns presented should be a good base for future elaboration of methods on how to influence adolescent sexual behaviour to minimise these risks.

This study was supported by grants from the National Comis sion on Aids and the National Board of Health and Welfare.

Preliminary data from this study have earlier been reported in the Journal of the Swedish Medical Association 1990;87:4296-8 (in Swedish).

1 Heymann DL, Chin J, Mann JM. A global overview of AIDS. In: Alexander NJ, Gabelnick HL, Spieler JM, eds. Heterosexual Transmission of AIDS. New York: Alan R Liss Inc, 1990;1-8.

2 Potts M, Feldblum PJ. Changing behaviour: Barrier methods in high-risk populations. In: Alexander NJ, Gabelnick HL, Spieler JM, eds. Heterosexual Transmission of AIDS. New York: Alan R Liss Inc, 1990;69-79.

3 Helmius G. Mature enough for sex?! English summary of Doctoral Thesis, Department of Sociology, University of Uppsala, 1990.

4 Centers for Disease Control. Premarital sexual experience among adolescent women, United States, 1979-1988. $M M W R$ 1990;39:929-32.

5 Official statistics of Sweden. Statistics Sweden, Stockholm,

6 Stenholm B. The Swedish school system. Stockholm: The Swedish Institute, 1984.

7 Anagrius C, Hallén A, Moi H, Persson E. Prevention of STDs and abortions- the present situation for medical care of STDs in Sweden. Semin Dermatol 1990;9:190-3.

8 National Board of Health and Welfare Drug Information Committee: Treatment of sexually transmitted disease. Uppsala, 1986: Report No 4.

9 Persson E. Family planning and prevention strategies for sexually transmitted diseases. Adv Contraception 1991; 7:181-6.

10 National Commission on AIDS: Information about HIV/ AIDS. Goals and strategy for public policy measures. 
Stockholm: Ministry of Health and Social Affairs, 1986. 11 Vogel J. The Swedish class society, class structure, social mobility and inequality. In: Living Conditions. Report No. 50. Stockholm: Statistics Sweden, 1987.

12 Andersson-Ellström A, Forssman L. Sexually transmitted diseases-knowledge and attitudes among young people. Developments in Sweden between 1986 and 1988 . Adolesc Health 1991;12:72-6.

13 Persson E, Holtzberg M, Edgardh $K$. Sexual experience, abortion and sexually transmitted diseases among young women at contraceptive clinic. Acta Obstet Gynecol Scand 1991;70:63-7.

14 Ramstedt K, Forssman L, Giesecke J, Granath F. Risk factors for Chlamydia trachomatis infection in 6810 young women attending family planning clinics. Int $J$ STD wIDS 1991 (in press)

15 UK Family Planning Research Network: Patterns of sexual behaviour among sexually experienced women attending family planning clinics in England, Scotland and Wales. British Journal of Family Planning 1988;14:74-82.

16 Andersch B, Milson I. Contraception and pregnancy amon young women in an urban Swedish population. Contraception 1982;26:211-9.

17 Riphagen FE, von Schoultz B. Contraception in Sweden. Contraception 1989;39:633-42.

18 Kegeles SM, Adler NE, Irwin CE. Adolescents and condoms. Am J Dis Child 1989;143:911-5.

19 Jarlbro G. Knowledge on Swedes' sexual habits (in Swedish) National Commission on AIDS Report. Stockholm, 1989.

20 Johnson AM, Wadsworth J, Elliot P, et al. A pilot study of sexual lifestyle in a random sample of the population of Great Britain. AIDS 1989;3:135-41.

21 Cates $W$. Teenagers and sexual risk taking: The best of times and the worst of times. $J$ Adolesc Health 1991;12:84-94.

22 Brooks-Gunn J, Furstenburg JR. Adolescent sexual behaviour. Am Psychol 1989;44:249-57. 